\title{
Caminhos do Significado em Atividades de Modelagem Matemática: um olhar sobre os interpretantes
}

\author{
Meaning's Routes in Activities of Mathematical Modeling: \\ a look on the interpretants
}

\author{
Karina Alessandra Pessoa da Silva* \\ Lourdes Maria Werle de Almeida**
}

\begin{abstract}
Resumo
Neste artigo apresentamos resultados de uma pesquisa na qual investigamos evidências de atribuição de significado em atividades de modelagem matemática. A pesquisa está fundamentada nos pressupostos teóricos da modelagem matemática e na semiótica Peirceana com foco na teoria dos interpretantes. A busca por evidências relacionadas à atribuição de significado é permeada pela análise dos interpretantes produzidos por um grupo de alunos de um curso de Licenciatura em Matemática no decorrer de etapas associadas ao desenvolvimento de atividades de modelagem. Por meio de tais interpretantes inferimos sobre a atribuição de significado para o problema e para a Matemática durante o desenvolvimento da atividade de modelagem analisada, traçando caminhos do significado.
\end{abstract}

Palavras-chave: Modelagem Matemática. Semiótica Peirceana. Interpretantes. Atribuição de Significado.

\begin{abstract}
In this article, we present results of a research in which we investigate evidence of assignment of meaning in mathematical modeling activities. The research is based on theoretical assumptions of mathematical modeling and on Peircean Semiotic focusing on theory of the interpretants signs. The search for evidence related to the attribution of meaning is permeated by the analysis of the interpretants produced by a group of students of a course degree in mathematics during steps associated with the development of modeling activities. Through such interpretants signs, we infer about the attribution of meaning to the problem and to mathematics during the development of the modeling activity analyzed, describing meaning's routes.
\end{abstract}

Keywords: Mathematical Modeling. Peircean Semiotic. Interpretants. Assignment of Meaning.

\footnotetext{
* Doutora em Ensino de Ciências e Educação Matemática pela Universidade Estadual de Londrina (UEL). Docente da Universidade Tecnológica Federal do Paraná (UTFPR), Londrina/PR, Brasil. Endereço para correspondência: Rua Joaquim Murtinho, 200, Jardim Novo Sabará, CEP: 86066-030, Londrina/PR, Brasil. Email: karinapessoa@gmail.com.

** Doutora em Engenharia de Produção pela Universidade Federal de Santa Catarina (UFSC). Pós-Doutorado em Educação Matemática pela UFSC. Docente da Universidade Estadual de Londrina (UEL), Londrina/PR. Endereço para correspondência: Rua Antonio Pisicchio, 155, apto 303, CEP: 86050-482, Londrina/PR, Brasil. Email: lourdes.maria @sercomtel.com.br.
} 


\section{Introdução}

Discussões referentes aos processos de ensino e de aprendizagem têm sido recorrentes na área da Educação Matemática. Neste contexto argumentações sobre a importância de se incorporar o desenvolvimento de atividades de modelagem às aulas de Matemática têm sido o foco de vários pesquisadores da área.

Dentre os aspectos que merecem atenção no que se refere à implementação de atividades de modelagem matemática está a atribuição de significado ao problema, à Matemática, que em alguma medida pode ser evidenciada nas ações, nas representações, nas argumentações dos alunos.

Considerando a ideia de que em uma atividade de modelagem parte-se de uma situação inicial (problemática) e obtém-se uma solução para esta situação, uma resposta ao problema, para além de ensinar Matemática, estamos em busca da solução para um problema no desenvolvimento da atividade. Assim, o problema também pode ser percebido como objeto de estudo em uma atividade de modelagem e evidenciar a atribuição de significado para este objeto pode constituir um importante estudo na linha de pesquisa de Modelagem Matemática. Neste sentido configura-se o aprender a resolver problemas e o aprender conceitos matemáticos como aspectos essenciais associados ao desenvolvimento de uma atividade de modelagem matemática.

Pesquisas que em alguma medida se remetem à atribuição/construção de significados no desenvolvimento de atividades de modelagem têm sido desenvolvidas por vários autores (CARREIRA; AMADO; LECOQ, 2011, BLOMHØJ; KJELDSEN, 2011, ALMEIDA, 2010).

$\mathrm{O}$ que, em termos gerais, é abordado nestes textos, diz respeito à busca de evidências da atribuição de significado para o problema, para a Matemática. No presente artigo argumentamos que esta busca por evidências pode se pautar na análise dos signos usados e/ou produzidos pelos alunos durante o desenvolvimento da atividade de modelagem. Ao tratar da análise de signos nos fundamentamos na teoria semiótica de Charles Sanders Peirce, particularmente nas suas construções e argumentações sobre os signos que se criam na mente do aluno - os interpretantes, e as inferências com relação à atribuição de significado a partir destes signos. Os interpretantes evidenciados nos registros escritos, nas falas e nos gestos que emergem durante o desenvolvimento de atividades de modelagem matemática constituem um acervo de dados que indicam aspectos relacionados à atribuição de significado pelo aluno (intérprete). 
Neste contexto, temos como objetivo investigar os caminhos do significado que parecem ser traçados por alunos quando desenvolvem atividades de modelagem matemática.

$\mathrm{Na}$ investigação consideramos as ponderações de Santaella (2007, p. 37), de que "a análise dos interpretantes deve estar alicerçada na leitura cuidadosa tanto dos aspectos envolvidos no fundamento do signo como nos aspectos envolvidos nas relações do signo com seu objeto". A metáfora do caminho vem ancorada nas assertivas de Colapietro (2004, p. 21) de que há caminho "quando houve um movimento ou pelo menos a perspectiva de movimento".

Subsidiamos nossas reflexões na análise do desenvolvimento de uma atividade de modelagem por um grupo de estudantes de um curso de Licenciatura em Matemática em uma disciplina de Modelagem Matemática na perspectiva da Educação Matemática. Tais análises conduzem a reflexões e considerações sobre os caminhos do significado no desenvolvimento de atividades de modelagem.

Levando em consideração esse encaminhamento, este texto está estruturado, além desta introdução, em quatro seções subsequentes. Na primeira tratamos da Modelagem Matemática e, a partir de uma busca na literatura, identificamos etapas que o intérprete pode percorrer para desenvolver uma atividade de modelagem. Em seguida, tratamos do significado na perspectiva da semiótica peirceana com foco nos interpretantes. Na terceira seção definimos os aspectos metodológicos que orientam nossa pesquisa e apresentamos a análise da atividade. Finalizamos apresentando os caminhos do significado na atividade analisada.

\section{Modelagem Matemática}

Quando tratamos de Modelagem Matemática, estamos nos referindo a atividades que têm como ponto de partida uma situação inicial (problemática) e como ponto de chegada uma situação final (solução para a situação inicial); no percurso da busca pela solução são utilizados procedimentos que caracterizam estratégias de ação do sujeito envolvido com a atividade em relação à situação inicial problemática. Tais estratégias de ação são associadas, de modo geral, a etapas da modelagem matemática. Neste artigo consideramos a compreensão de Blum e Niss (1991) que defendem que a atividade de modelagem requer do modelador algumas articulações entre a situação do mundo real e a Matemática. Neste sentido, os autores defendem que em uma atividade de modelagem matemática

[...] o ponto de partida é um problema também chamado de situação-problema real. Esta situação tem de ser simplificada, idealizada e estruturada, por meio de condições e pressupostos apropriados e também pelos interesses do modelador. Isto 
conduz a um modelo real da situação original que, por um lado, ainda contém traços essenciais da situação original, mas, por outro lado, já está esquematizado e (se possível) permite uma aproximação com aspectos matemáticos.

O modelo real tem de ser matematizado, ou seja, os dados, conceitos, relações, condições e pressupostos são traduzidos em matemática. Assim, resulta um modelo matemático da situação original. [...]

O processo de resolução do problema continua no contexto da matemática, e as conclusões fundamentam-se em cálculos, verificações e aplicação de métodos e resultados matemáticos conhecidos, bem como podem abranger o desenvolvimento de novos conceitos, etc. [...] De modo geral, alguns resultados matemáticos são obtidos.

Estes resultados têm de ser re-traduzidos para o mundo real, ou seja, ser interpretados em relação à situação original. Ao fazê-lo, o modelador também valida o modelo, ou seja, decide se o utiliza para os fins para quais foi construído. Ao validar o modelo, discrepâncias de vários tipos podem ocorrer, o que pode conduzir a uma modificação do modelo ou a sua substituição por um novo. Em outras palavras, o processo de resolução de problemas pode exigir a volta ao ciclo várias vezes. Se, eventualmente, um modelo satisfatório foi encontrado, o modelador pode usá-lo como base para fazer previsões, tomar decisões ou ações. [...] (BLUM; NISS, 1991, p. 38-39).

Levando em consideração o desenvolvimento de atividades de modelagem como descrito por Blum e Niss (1991), as etapas caracterizadas em Blum (2011), bem como adaptações no esquema explicativo proposto por Almeida, Silva e Vertuan (2012), apresentamos na Figura 1 a configuração para uma atividade de modelagem matemática usada neste artigo.

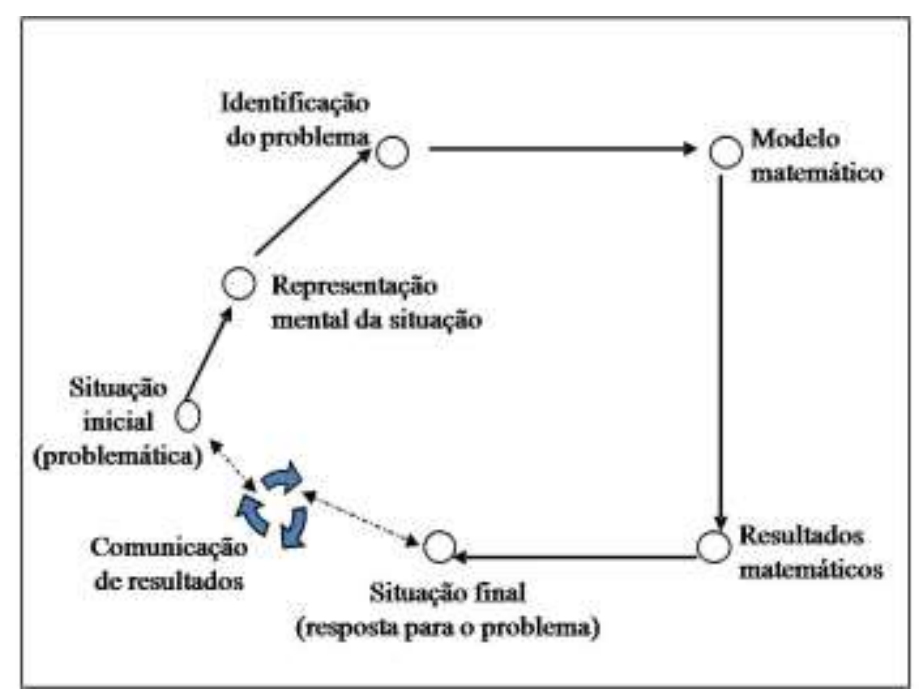

Figura 1- Etapas do desenvolvimento de atividades de modelagem matemática Fonte: Construída pelas autoras para o artigo.

De forma geral, em pesquisas relativas à Modelagem Matemática na área de Educação Matemática (MAAß, 2006, STILLMAN et al, 2007, BLUM, 2011, ALMEIDA; SILVA, 2012), a gênese da atividade está na formulação e resolução de um problema. Neste contexto, consideramos problema como uma situação em que o sujeito deseja fazer algo, mas desconhece, a priori, os procedimentos ou encaminhamentos necessários para obter a solução 
(POGGIOLI, 2001); e modelo matemático como um sistema conceitual, descritivo ou explicativo, expresso por meio de uma linguagem ou uma estrutura matemática, com a finalidade de descrever o comportamento de outro sistema e permitir a realização de previsões sobre este (LESH, 2010).

Para além de resolver um problema identificado na situação inicial, os envolvidos com uma atividade de modelagem precisam identificar, fora do âmbito da Matemática, uma situação-problema cuja abordagem possa se dar mediante o uso da Matemática. Neste sentido, existem pesquisas que defendem que tanto professor quanto alunos podem ser responsáveis pela escolha da situação. O que se destaca é a forma como a busca de informações é efetivada quando os alunos se envolvem com atividades desta natureza.

Diniz e Borba (2012), neste contexto, evidenciaram um crescente número de atividades de modelagem que se utilizam de informações coletadas na internet, como gráficos, pictogramas ou fórmulas. Esses autores caracterizam tais informações como dados prontos, "que já estão organizadas e que, nem sempre, trazem uma explicação sobre como foram coletadas e organizadas" (DINIZ; BORBA, 2012, p. 937). No entanto, os autores destacam que o engajamento dos alunos com o objetivo de identificar as relações que não estão disponibilizadas e que podem complementar a compreensão dos dados prontos "parecem gerar o mesmo resultado que a coleta de dados em campo" (p. 955). Neste sentido, entendemos que uma atividade de modelagem abordada por meio de informações prontas não inviabiliza o trabalho investigativo permeado pelas etapas como caracterizadas para uma atividade de modelagem matemática.

Neste artigo apresentamos uma atividade de modelagem desenvolvida em sala de aula por grupos de alunos que se utilizaram de dados prontos, apresentados em uma revista brasileira de caráter cultural e científico. Nosso intuito é inferir sobre os caminhos da atribuição de significado para o problema e para os objetos matemáticos que emergiram durante o desenvolvimento desta atividade. A identificação dos caminhos do significado se faz relevante considerando que sinaliza como se dá a atribuição de significado no âmbito de atividades de modelagem, bem como dá indícios do potencial de atividades de modelagem para esta atribuição. Nestes encaminhamentos, nos fundamentamos na teoria dos interpretantes, proposta na semiótica peirceana.

\section{Significado em Peirce: foco nos interpretantes}


Discussões com relação à noção de significado têm permeado pesquisas nas mais diversas áreas. Dentre as questões que são mais debatidas entre os pesquisadores destacam-se: O que constitui o significado?; Significado pode ser descrito como a ação de significar? Embora possamos nos deparar com diversas teorias acerca da noção de significado, esse assunto não se encontra esgotado.

Ao tratarmos de questões relativas à atribuição de significado em atividades de modelagem matemática nos pautamos na semiótica peirceana, desenvolvida por Charles Sanders Peirce (1839-1914). Segundo estudiosos da semiótica peirceana (OTTE, 2001, HOFFMANN, 2004, COLAPIETRO, 2004, SANTAELLA, 2008, NÖTH, 2008), a atribuição de significado para o objeto está intrinsecamente relacionada aos interpretantes enquanto signos produzidos na mente de um intérprete. Hoffmann (2004, p. 198), neste contexto, afirma que uma característica relevante da semiótica de Peirce é justamente o reconhecimento do papel do interpretante na atribuição do significado.

Objeto, interpretante e signo (também denominado por representámen na semiótica peirceana) são elementos constituintes da tríade semiótica de Peirce, na qual o signo estabelece uma mediação entre objeto e interpretante. $\mathrm{O}$ objeto é caracterizado por Peirce (2005, p. 48) como "uma coisa singular existente e conhecida ou que se acredita tenha anteriormente existido ou que se espera venha a existir". Já o signo, segundo Peirce (1972), tem a função de representar seu objeto para alguém (intérprete), criando na mente desse alguém um outro signo, o interpretante. Esse novo signo é um processo racional que se cria na mente do intérprete. O interpretante, segundo Santaella (2005, p. 43), "não é qualquer signo, mas um signo que interpreta o fundamento". É por meio da interpretação evidenciada no interpretante que o fundamento do signo revela algo sobre o objeto existente.

O interpretante, como afirma Santaella (2007), corresponde ao "efeito interpretativo que o signo produz em uma mente real ou meramente potencial” (p. 23). Neste sentido, cada signo, na mente do intérprete, gera um interpretante que, por sua vez, funciona como representámen de um novo signo, em um processo de geração de interpretantes num ciclo ad infinitum. O processo de geração de interpretantes, em sentido peirceano, constitui a semiose.

Para além de ser um processo de geração, Colapietro (2004) sustenta que a semiose também se constitui em um processo de determinação triadicamente mediado, ou seja, "um processo no qual o signo determina seu interpretante de tal maneira, levando adiante o jeito como o próprio signo tem sido, ou simplesmente poderia ser, determinado por seu objeto" (p. 21). Olhar para o interpretante é, portanto, uma possibilidade de fazer inferências sobre a atribuição de significado para o objeto pelo intérprete. 
Colapietro (2004, p. 14) afirma que a semiótica peirceana incluiu "uma elaborada teoria do interpretante e, com isso, uma explicação variada de significado". O significado é citado por Peirce em diferentes circunstâncias. Para o autor, o "significado não é uma ideia que o símbolo evoca na mente, mas consequência da conduta que gera nos homens (racionais)" (PEIRCE, 1972, p. 18); "significado deve envolver uma referência, a intenção" (PEIRCE, 1989, p. 16, grifo do autor); emprega o significado como "numa ideia de sentimento ou predominantemente numa ideia de atuar e ser atuado" (PEIRCE, 2005, p. 194); “significado é aquilo que é pretendido, seu propósito" (PEIRCE, 2005, p. 169); "significado é o interpretante declarado de um símbolo" (PEIRCE, 2005, p. 222); "significado de um termo é a concepção que ele veicula" (PEIRCE, 2005, p. 254).

O procedimento adotado por Peirce para reconstruir ou explicar significados consiste no estabelecimento de um conjunto de condições para uma dada situação na qual uma operação definida produziria um resultado definido. Ou seja, para determinar o que um conceito significa ou "para deixar claro o significado de uma ideia devemos tentar interpretar cada noção traçando suas consequências práticas" (PEIRCE, 1972, p.21). Uma maneira de evidenciar essas consequências é analisar os símbolos produzidos pelos intérpretes para o mesmo objeto. Se ocorrerem mudanças significativas para os símbolos, possivelmente há um progresso na atribuição de significado para o objeto, conforme afirma Peirce (2005, p. 40) “o corpo de um símbolo transforma-se lentamente, mas seu significado cresce inevitavelmente, incorpora novos elementos e livra-se de elementos velhos".

Nessa assertiva também podemos evidenciar que a familiaridade com os símbolos possibilita um progresso no que tange ao incremento do significado para o objeto. Peirce (1989) remete-se à familiaridade e à experiência prévia quando trata da representação do objeto pelo signo.

Para ler o signo, e distinguir um signo de outro, o que se faz necessário são
percepções sutis e familiaridade com os concomitantes habituais de tais aparências,
e com as convenções do sistema de signos. Para conhecer o objeto, o que é preciso é
a experiência prévia desse objeto individual. O objeto de cada signo é um indivíduo
[...] conhecer o interpretante, que é o que o signo ele próprio expressa, pode requerer
o mais alto poder do raciocínio (PEIRCE, 1989, p. 61).

Silva (2013), percorrendo as diferentes obras de Peirce e de muitos de seus interpretadores, fez um levantamento de afirmações do autor com relação ao significado e concluiu que, de modo geral, há evidências de atribuição de significado para o objeto por meio de:

familiaridade que o intérprete possui com o dado objeto, se este já faz parte de sua realidade ou contexto; na intenção de significar o objeto, em que ocorre, a partir de uma referência, uma articulação deste objeto com o contexto em que este é utilizado; 
como uma ideia que se remete ao objeto, de atuar e ser atuado; como consequência futura para abarcar o objeto, em que as consequências práticas estabelecem destaque entre pensamento e ação; por meio de experiência colateral com o objeto, ou seja, da intimidade prévia com aquilo que o signo denota (SILVA, 2013, p. 69).

A partir desses aspectos abordados sobre significado e considerando a semiose como processo de geração e de determinação de interpretantes, buscamos indícios de atribuição de significado para o objeto pelo intérprete em uma atividade de modelagem matemática desenvolvida por alunos trabalhando em grupo. Para tanto, corroboramos as conclusões apontadas em Silva (2013) e, olhando para os signos dos alunos nas diferentes etapas de desenvolvimento de uma atividade de modelagem como caracterizado na Figura 1, traçamos os caminhos do significado do aluno nessa atividade.

\section{Os interpretantes em uma atividade de modelagem matemática}

A análise empreendida neste artigo leva em consideração os interpretantes produzidos por três alunos do $4^{\circ}$ ano de um curso de Licenciatura em Matemática durante o desenvolvimento de uma atividade de modelagem na disciplina de Modelagem Matemática, ministrada por uma das autoras deste texto com a participação da outra autora como aluna de doutorado. Neste sentido, levamos em consideração signos escritos, falados e gesticulados que se remetem ao problema e ao objeto matemático durante o desenvolvimento da atividade, bem como o que os alunos dizem, em entrevista, sobre o problema e o objeto matemático a partir dos signos que produziram.

As informações que subsidiam as argumentações com relação à atribuição de significado foram coletadas por meio de vídeos, gravações em áudio, relatório da atividade dos alunos, questionário e entrevista a posteriori. Para fazermos menção aos participantes da pesquisa utilizamos a letra E seguida de um número (E1, E2, E3) para cada estudante e P para a pesquisadora.

A atividade que descrevemos está relacionada à situação inicial (problemática) consumo de cigarros por pessoa durante um ano e foi desenvolvida em sala de aula durante 4horas/aula da disciplina.

Os alunos entraram em contato com dados prontos sobre consumo anual de cigarros por pessoa no período de 1950 a 2007 conforme indica a Figura 2.

Um primeiro procedimento dos alunos nesse caso seria associar aos dados da figura os dados da Tabela 1. O que essa tabela claramente indica é a inclusão do ano de 2010 (última linha da tabela) que não consta na Figura 2. A previsão de consumo de cigarros para o ano de 
2010 foi realizada pelos alunos a partir da observação de que no período entre 1990 e 2000 o decrescimento do consumo anual de cigarros por pessoa corresponde a aproximadamente 13,75\%; já para o período de 2000 a 2007, o percentual cai para 7,86\%. Considerando como hipótese que o decaimento de 7,86\% do último período foi igualmente distribuído entre os sete anos, puderam considerar que o consumo diminuiu em $1,12 \%$ ao ano nesse período. Supondo que este percentual se manteve no período entre 2007 e 2010 , concluíram que a quantidade de cigarros consumida por pessoa em 2010 foi de 813 cigarros conforme indica a última linha da Tabela 1.

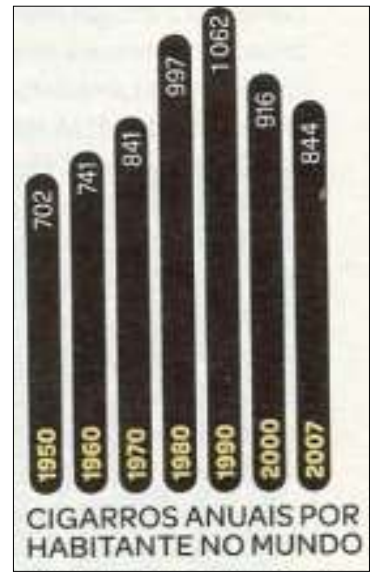

Tabela 1- Número de cigarros consumidos por ano por pessoa

\begin{tabular}{c|c}
\hline Ano $(\mathrm{t})$ & Número de cigarros \\
\hline 1950 & 702 \\
1960 & 741 \\
1970 & 841 \\
1980 & 997 \\
1990 & 1062 \\
2000 & 916 \\
2010 & 813 \\
\hline \multicolumn{2}{c}{ Fonte: Relatório dos alunos (2011). }
\end{tabular}

Fonte: Relatório dos alunos (2011).

Figura 2- Consumo de cigarros no mundo

Fonte: Revista Super Interessante, agosto de 2009, p.35.

A partir desse tratamento e dessa complementação nos dados já incorporando, embora de forma implícita, hipóteses sobre o problema, os alunos investiriam então na construção de modelos matemáticos.

Com esta intenção, o desenvolvimento da atividade de modelagem foi permeado por simulações dos alunos, considerando que o decrescimento observado no período de 1990 a 2010 poderia ser estudado por meio de diferentes modelos matemáticos, a saber - linear, exponencial e quadrático.

Para iniciar o desenvolvimento da atividade, o primeiro procedimento dos alunos foi inteirar-se da situação problemática com o intuito de compreender as informações apresentadas, conforme indica o diálogo:

\section{E3: Tem uma regrinha não tem?}

E1: Mas olha, o valor com relação ao ano, não está em proporção?

[e começam a olhar para a situação a partir das informações sobre proporção que foi utilizada para montar a Tabela 1]

E2: A gente viu que de dois mil e oito, dois mil e nove a taxa diminuiu, mas e a partir de dois mil e dez? Não pode afirmar nada!

E1: É o que a gente vai utilizar como hipótese... é essa taxa de decaimento.

E2: Então vamos considerar que continue na mesma taxa de decaimento então.

E1: Porque se eu fosse fazer uma função linear daqui para cá [apontando para anos a partir 
de 1990 indicados nos pontos do plano cartesiano que E2 traçou a partir dos dados da Figura 2 e que é apresentada na Figura 3], eu ia considerar essa taxa, essa taxa que decai aqui. [e continuam a busca por uma regularidade nessas informações da situação-problema].

E3: Mas o que podemos estudar com isso? Qual é o problema?

E1: É... o problema...

E2: Se a gente pensar na questão de diminuição de consumo, a gente poderia pensar em que ano o número de cigarros consumidos volta a ser o mesmo de mil novecentos e cinquenta que é o menor valor!

E3: Setecentos e dois?

E2: Isso mesmo, a menor quantidade de cigarros consumidos. Nossa!!! [espanto em ver que embora o número de cigarros seja menor, ainda é uma quantidade elevada].

[...]

E3: Mas a taxa de decaimento de um mil novecentos e noventa para dois mil é maior do que no outro período, será que a gente pode dizer que esse decaimento é linear?

E2: E daí coloca ou não coloca a taxa de decrescimento como hipótese?

E1: É... nessa parte [apontando para anos a partir de 1990] parece exponencial também.

E2: Mas a tabela e a situação falam apenas da parte do decaimento. E é o que a gente quer estudar no nosso problema!

[e continuam a busca pela regularidade nessas informações da situação-problema]. (Gravação áudio-visual, 2011).

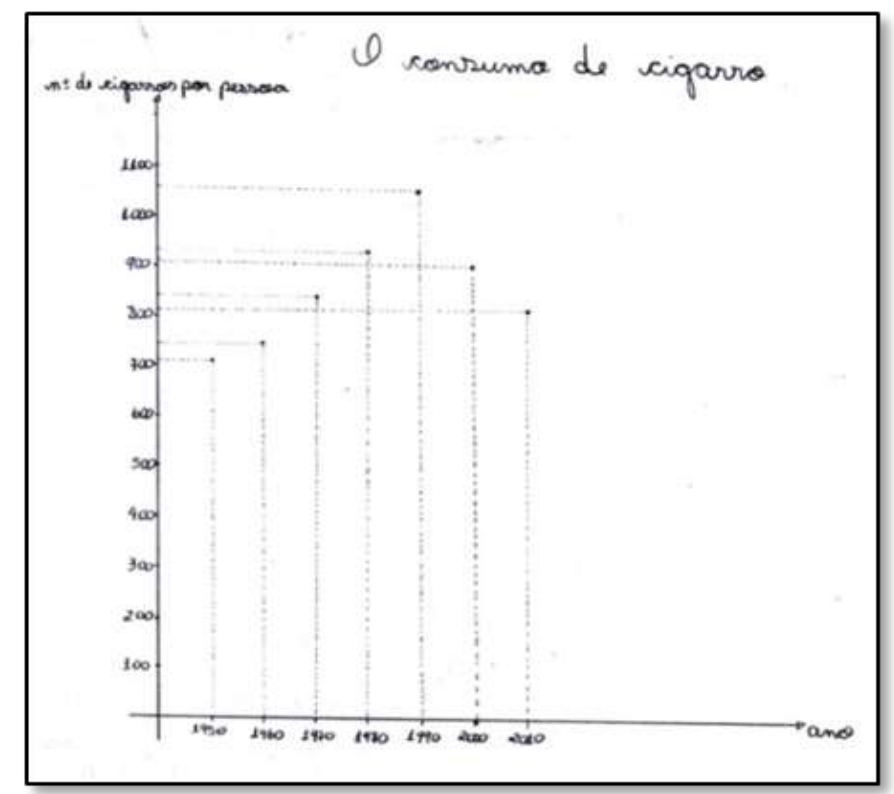

Figura 3- Registro de E2 para a tendência dos dados apresentados na atividade de modelagem Fonte: Relatório entregue por E2 (2011).

A partir dessa inteiração os alunos elaboram discussões sobre as informações quantitativas apresentadas no pictograma (Figura 2) com a intenção de visualizar nos dados alguma regularidade. No entanto, a discussão ficou em torno da taxa de proporção utilizada nos cálculos para a obtenção do número de cigarros para o ano de 2010. Uma mudança nas discussões sobre a utilização dos dados ocorre quando E1, analisando os pontos no plano cartesiano (Figura 3) a partir do ano de 1990, apresenta seus argumentos com relação à interpretação da situação-problema: "É o que a gente vai utilizar como hipótese... é essa taxa de decaimento / Porque se eu fosse fazer uma função linear / parece exponencial também” 
(E1, gravação áudio-visual, 2011), culminando na definição do problema por E2 “[...] em que ano o número de cigarros consumidos volta a ser o mesmo de mil novecentos e cinquenta que é o menor valor!” (E2, gravação áudio-visual, 2011). Com a abordagem da situação, em grupo, os alunos definem um problema a ser estudado, levando em consideração a diminuição do consumo de cigarros como apresentado no relatório entregue (Figura 4) e simplificando o uso de informações.

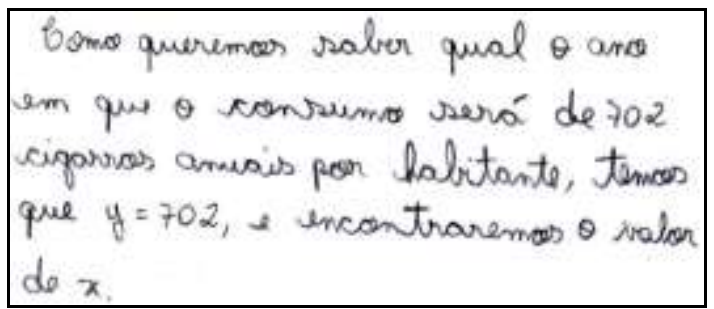

Figura 4- Registro de E1 para a definição do problema para atividade de modelagem Fonte: Relatório entregue por E1 (2011).

$\mathrm{Na}$ produção de seus interpretantes, E1 utiliza-se de argumentos com relação aos objetos matemáticos, função linear e função exponencial. Nesse sentido, para E1 a tendência dos dados, representados no plano cartesiano para anos a partir de 1990 é um signo que representa tais objetos matemáticos. Já E2 está engajado em uma interpretação que leva em consideração o problema a ser estudado conforme indica sua fala: "Mas a tabela e a situação falam apenas da parte do decaimento. E é o que a gente quer estudar no nosso problema!" (E2, gravação áudio-visual, 2011).

Embora representem todos os dados da Figura 2 no plano cartesiano (Figura 3), os alunos entendem que, para a abordagem do problema, somente o intervalo decrescente do gráfico é considerado, como proposto por E2, uma vez que a situação-problema apresentava uma discussão sobre o decaimento do consumo de cigarros por pessoas nos últimos anos, bem como sobre políticas governamentais que proíbem o fumo em alguns ambientes. Com isso, abandonam as discussões sobre proporção estabelecidas inicialmente e não utilizam tais informações para a dedução do modelo matemático. Ao serem questionados sobre o abandono desta abordagem em entrevista a posteriori, os alunos argumentam que:

[...]

P: Vocês falaram que as porcentagens apresentadas no texto não tinham nada a ver para a dedução do modelo... por que?

E1: Porque quando a gente pega um texto acha que todas as informações têm que ser usadas...

E2: Exatamente!

E1: Depois a gente viu que realmente a gente não ia precisar de nada também [risos]

E2: Engraçado isso!

$P:$ A interpretação dos dados?

E2: Aham... que a gente acaba confundindo... porque acho que tinham muitos...

E1: Trocou, a gente se perde também... fica um pouco confuso... tipo [folheando a resolução e 
se referindo a exemplos de situações-problema que já tinham resolvido em sala de aula] (Entrevista gravada em áudio, 2011).

Os alunos deixam evidente que não estão acostumados a lidar com situações em que precisam realizar simplificações das informações para a dedução do modelo para o problema a ser estudado. Quando se deparam com uma atividade que apresenta várias informações tentam utilizar todos os dados apresentados, sem se aterem ao problema que estabeleceram. Além disso, procuram em anotações anteriores uma espécie de protocolo para desenvolver a atividade e se deparam com uma situação diferenciada. No âmbito escolar, Manechine e Caldeira (2006, p. 3) afirmam que, "na medida em que o educando vai se familiarizando e apreendendo determinados signos universais, esses vão se tornando objetos referenciais para conexão, relação e apropriação de novos signos". Neste caso, a familiaridade com o desenvolvimento de atividades de modelagem na disciplina viabiliza um protocolo para o encaminhamento da atividade, no entanto, a simplificação e interpretação das informações dependem de quem lida com a atividade.

Da necessidade de realizarem simplificações para a dedução do modelo matemático, os alunos estabeleceram algumas hipóteses que de certa forma se configurariam em uma solução para o problema, ou seja, estudar quando as pessoas estarão fumando menos cigarros ao ano, ou pelo menos se aproximando do número de cigarros fumados no ano de 1950. Para tanto, abordaram o estudo por meio de função linear e função exponencial (Figura 5).

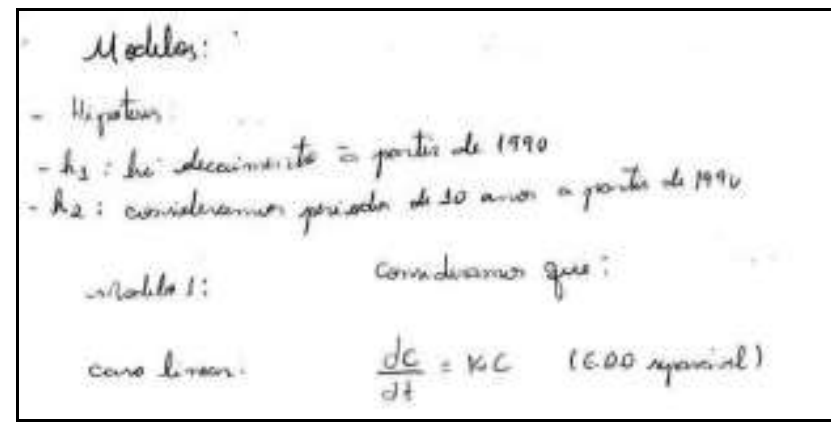

Figura 5- Registro de E1 para a definição de hipóteses para a atividade de modelagem Fonte: Relatório entregue por E1 (2011).

Uma abordagem por meio de uma função quadrática também foi ensaiada pelos alunos, no entanto, perceberam que um modelo deste tipo não seria adequado uma vez que com os dados que tinham o ponto de mínimo era superior a 702 cigarros. Neste sentido, ao estabelecerem relações entre os objetos matemáticos que iriam utilizar para obter uma solução para o problema, os alunos lançaram mão de signos que, segundo Peirce (1972), representam o objeto (problema) de certa forma e capacidade. 
As simplificações, segundo Borromeo Ferri (2006), auxiliam na definição do problema a ser estudado em atividades de modelagem. Além de simplificações com relação ao que seria utilizado para a resolução do problema, os alunos utilizaram de variável auxiliar para simplificar os cálculos matemáticos e trabalhar com unidades ao invés de milhares, conforme diálogo durante a resolução.

E2: Acho bom a gente considerar o período como variável auxiliar. Você utilizou o período E1?

E1: Aham [afirmando].

E3: Para a gente fazer as continhas, acho bom a gente começar a montar uma tabela.

E2: Aham [afirmando].

E1: O período é de dez em dez anos.

E3: Vamos fazer a tabelinha então e começar a deduzir um modelo linear!

E1: A partir do método dos mínimos quadrados dá para a gente definir essa função.

E3: Beleza, então vamos...

[começam a realizar individualmente os cálculos para encontrar o modelo linear por meio do método dos mínimos quadrados] (Gravação áudio-visual, 2011).

A partir das considerações que realizam sobre a hipótese e as variáveis, o trio inicia a dedução do modelo matemático, representado pela função linear (Figura 6), ou seja, consideram como hipótese que o decrescimento é linear - [...] começar a deduzir um modelo linear (E3, gravação áudio-visual, 2011). As considerações que utilizaram para a dedução do modelo matemático são definidas em conjunto, mas as relações matemáticas e os cálculos matemáticos foram realizados individualmente e conferidos entre os alunos. Neste artigo, utilizamos registros dos três alunos do mesmo trio por estarem em consonância entre si. Pelas imagens gravadas em vídeo, enquanto E1 resolve, os outros membros do trio discutem a situação-problema, fazendo a leitura das informações que receberam e copiam a resolução de E1. 


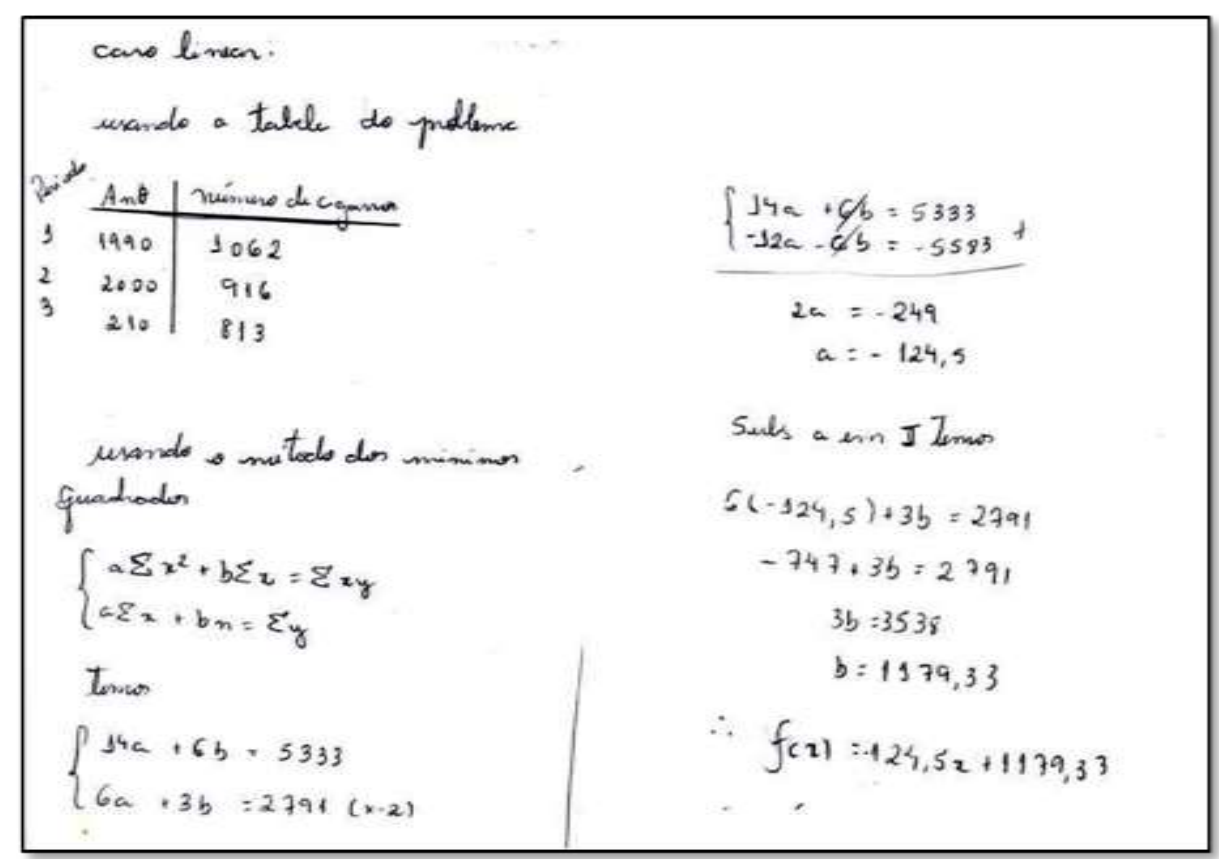

Figura 6- Registro de E1 na obtenção do modelo linear na atividade de modelagem Fonte: Relatório entregue por E1 (2011).

Na dedução do modelo linear (Modelo 1), os alunos utilizam o método dos mínimos quadrados. Ao serem questionados na entrevista sobre o porquê utilizaram esse método ao invés de escolher dois pontos, por exemplo, E1 responde: "Seria muito simples deduzir o modelo matemático usando dois pontos. A gente queria fazer algo utilizando técnicas que aprendemos na graduação... só que se tivéssemos escolhido dois pontos teria sido mais rápida a resolução!" (E1, entrevista gravada em áudio, 2011). Neste caso, a experiência colateral - a "intimidade prévia com aquilo que o signo denota" (PEIRCE, 1989, p. 61) - , com os signos universais do método dos mínimos quadrados corresponderam a objetos referenciais (MANECHINE; CALDEIRA, 2006) para a abordagem do objeto matemático função linear.

A partir das considerações sobre o uso do método dos mínimos quadrados para determinar a função linear, E1 explicita o signo que tinha em mente para desenvolver a atividade, o que, de acordo com afirmações de Miskulin et al (2007), caracteriza o interpretante. Para os autores "um signo só é signo porque é interpretado por alguém, pelo intérprete e este cria um novo signo em sua mente, o interpretante, que é, na realidade, a ideia que o intérprete tinha do signo original" (MISKULIN et al, 2007, p. 5). Esses interpretantes produzidos por E1 são indícios de que a função linear e sua obtenção por meio do método dos mínimos quadrados têm significado para esse aluno numa perspectiva de que a atribuição de significado está associada a uma intenção e a uma indicação de familiaridade com o objeto pelo intérprete. 
O próximo procedimento dos alunos foi, a partir do modelo matemático obtido com a hipótese de que a partir de 1990 o decrescimento é linear $(f(x)=124,5 x+1179,33)$, responder o problema - Qual o ano em que o consumo será de 702 cigarros anuais por habitante? - (Figura 7). Quando questionados sobre esse procedimento, E2 respondeu: “A gente só pensava em responder o problema. Tínhamos o modelo [risos], já queríamos saber logo a resposta e depois a gente falava... ai... tem que validar esse modelo [risos]" (E2, entrevista gravada em áudio, 2011). Para esse aluno, o significado atribuído ao problema correspondeu à intenção de apresentar uma resposta e findar a atividade. A resposta ao problema é entendida, segundo Almeida, Silva e Vertuan (2012), como uma interpretação em que "o aluno se depara com a necessidade de comparação e distinção de ideias, generalização de fatos, articulação de conhecimentos de diferentes áreas" (ALMEIDA; SILVA; VERTUAN, 2012, p. 18).

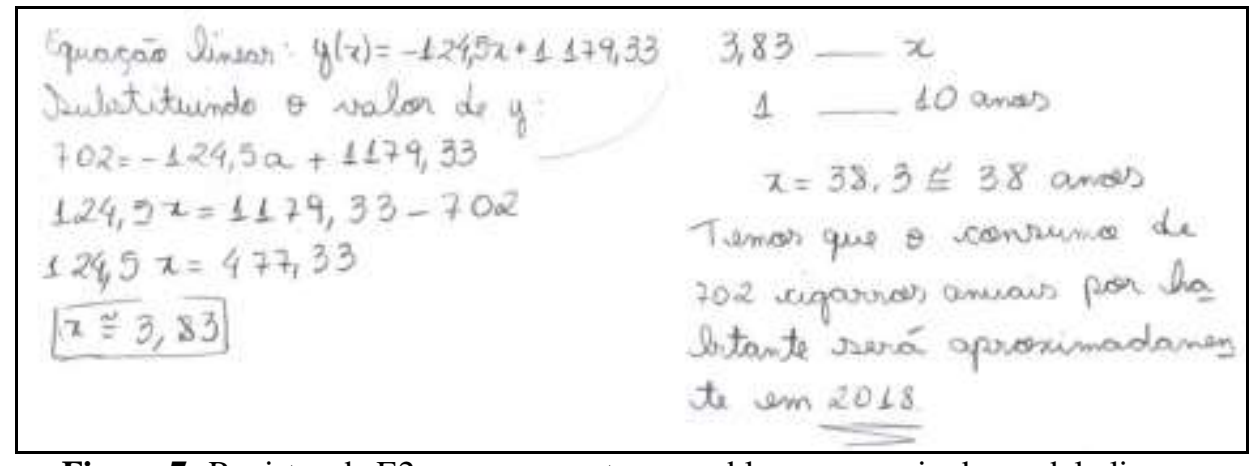

Figura 7- Registro de E2 para a resposta ao problema por meio do modelo linear Fonte: Relatório entregue por E2 (2011).

Esse fato evidencia que o objeto de estudo dos alunos na atividade de modelagem era o problema a ser resolvido, cuja resposta é de que no ano de 2018 o número de cigarros consumidos por habitante será de aproximadamente 702 cigarros. Se o modelo matemático de alguma forma pudesse responder o problema, esse era tomado pelos alunos como um modelo que representava a situação em estudo. Isso corrobora com a caracterização de modelo matemático atribuído por Davis e Hersh (1995) em que os autores afirmam que uma forma de caracterizar um modelo é considerá-lo bom ou ruim, simplista ou sofisticado, útil ou inútil com relação ao que ele está representando. Esta caracterização viria em consequência da capacidade que o modelo tem de apresentar uma resposta ao problema. Neste caso, se a resposta que o modelo produz é aceitável, então o modelo é bom, é útil.

Outro encaminhamento para a construção de um modelo matemático para buscar evidências com respeito à época em que novamente o consumo anual se reduziria aos 702 cigarros foi considerar a hipótese de que a taxa de variação da quantidade de cigarros consumidos por ano é proporcional ao número de cigarros consumidos em cada ano. Esta 
hipótese, que em linguagem matemática, é a equação diferencial separável de primeira ordem consta da Figura 8.

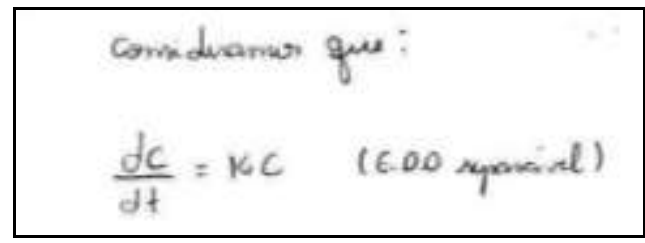

Figura 8 - Hipótese de E1 para o problema

Fonte: Relatório entregue por E1 (2011).

A resolução desta equação conduz a uma solução que descreve o decrescimento do consumo de cigarros por um modelo exponencial conforme mostram os registros dos alunos na Figura 9. Isto trouxe a tona o que E1 já pensava no início do desenvolvimento da atividade: “É... nessa parte [apontando para anos a partir de 1990] parece exponencial também” (E1, Gravação áudio-visual, 2011).

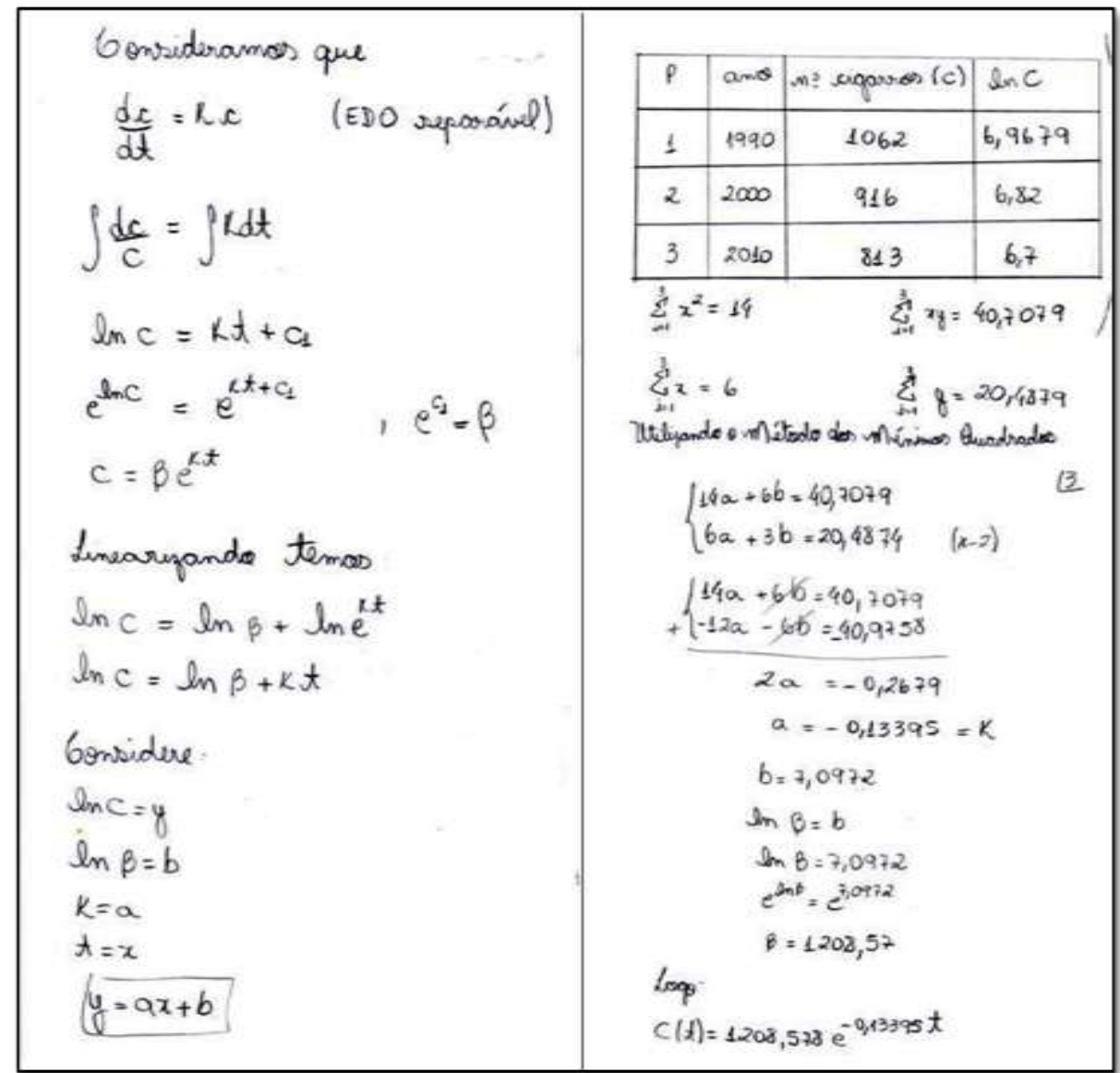

Figura 9- Registro de E2 na obtenção do modelo exponencial Fonte: Relatório entregue por E2 (2011).

O uso de equações diferenciais ordinárias nesse caso pode estar relacionado à familiaridade dos alunos com esse objeto matemático, pois conforme relato de E1: "A gente sabe que o tempo é uma função contínua e na situação decresce exponencialmente e isso fez com que a gente utilizasse EDO, pois já vimos isso em outros momentos [referindo-se à 
disciplina de Equações Diferenciais e a atividades de modelagem que já haviam realizado]" (E1, entrevista gravada em áudio, 2011). O método dos mínimos quadrados consiste em experiências prévias que os alunos já tiveram com tal procedimento, tanto que o utilizaram na dedução do modelo linear.

Os registros produzidos pelos alunos correspondem a signos que denotam o objeto matemático função exponencial. Uma vez obtido o modelo, os alunos realizaram sua validação para posteriormente utilizá-lo para responder o problema (Figura 10). Quando questionados por que agiram de forma diferente para esse modelo, E1 argumentou: "Isso porque na função linear era fácil de imaginar como seria o decrescimento então os dados davam para visualizar. Agora na função exponencial não dava, então a gente não tinha certeza de que estava certa... então a gente foi validar o modelo antes de utilizá-lo para darmos a resposta” (E1, entrevista gravada em áudio, 2011). Isso denota que a familiaridade dos alunos com função linear é maior do que com a função exponencial, pelo menos no que consiste na visualização via expressão algébrica.

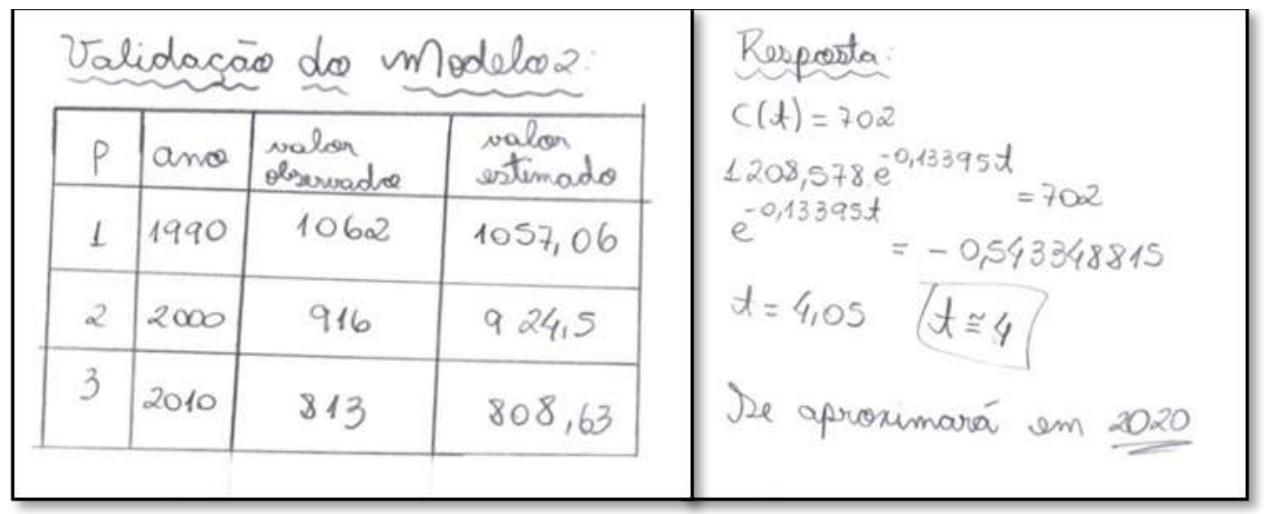

Figura 10- Registros de E2 para a validação e para a resposta do problema obtida por meio do modelo exponencial

Fonte: Relatório entregue por E2 (2011).

A validação resulta de um efeito interpretativo que o modelo produz no aluno, ou seja, o aluno interpreta, avalia a solução e é capaz de decidir se o modelo é adequado ou não. Neste sentido, a validação é um interpretante que indica o significado do modelo para esse aluno.

Por meio desse interpretante temos, portanto, indícios de que os alunos atribuem significado para o objeto matemático função exponencial, considerando que características dessa função correspondem ao comportamento do consumo de cigarros no decorrer do tempo. Embora entendam que a tabela e a expressão algébrica são signos que representam, sob certo aspecto, o objeto e que não são suficientes para representar todas as características desse objeto, os alunos não fizeram menção a outro signo que possa estar relacionado, por exemplo, 
o gráfico da função. Quando questionados sobre o não uso do gráfico, os alunos apresentam algumas argumentações durante a entrevista:

$[\ldots]$

P: Vocês traçaram a tendência dos dados no plano [referindo-se à Figura 3], mas vocês não fizeram a representação gráfica do modelo!

E2: Não... fizemos só num rascunho, né, assim bem por cima.

E1: É não consigo!

E2: [risos] é mas nós não colocamos no trabalho, foi só para visualizar assim meio por cima, daí foi bem um esboço mesmo.

$P$ : Isso é uma coisa que a gente percebe que as pessoas não fazem, mas por que vocês acham que a representação gráfica... assim de vocês, por que vocês acabam não fazendo?

E2: Ai... porque eu acho assim.. para ser bem sincera... algo para fazer manualmente exige cuidado, porque senão a análise que era para ser feita acaba dando errado, mas eu acho super importante... eu acho fundamental o gráfico para visualização, que às vezes tá aquele monte... não sei se é porque eu sou meio lerdinha sabe... [risos] então para eu visualizar, eu preciso de uma coisa mais concreta. Às vezes, somente com os dados eu não consigo visualizar o que está se falando, o comportamento que tá tendo. Então eu acho super importante.

P: Mas aqui dava para visualizar o comportamento dessas curvas?

E2: Aham

$P:$... desses dois modelos e fazer uma análise!

E2: Mas acabou que a gente não fez!

E1: A gente não fez. Uma pelo tempo e outra assim pelos valores dos dados, aí a gente ia ter um gráfico assim... sei lá... eu não sou muito caprichoso para fazer um gráfico com valores altos e compactar os intervalos, também achei que isso iria prejudicar...

P: A escala?

E1: A escala... daí eu pensei assim e optei por não e só analisar mesmo a validação.

E2: Mas se pudesse usar...

E1: ... o curve...

E2: ... o curve... já ia [risos] ser a primeira opção... já ia olhar o gráfico.

$P$ : Já ia influenciar um monte.

E1: Ia influenciar um monte [risos] (E1; E2, entrevista gravada em áudio, 2011).

Os alunos não utilizaram o recurso gráfico para representar o modelo matemático e fazer uma análise sobre o decrescimento da função exponencial. No entanto, os interpretantes enunciados, principalmente por E1 e E2, sinalizam que o não uso do gráfico não consiste em possível falta de compreensão do que é uma função exponencial, mas uma falta de habilidades para fazer a construção do gráfico sem o uso de uma ferramenta computacional. O fato de E1 ter dificuldade para utilizar escalas para a construção do gráfico denota uma falta de familiaridade com a manipulação do signo. Segundo Peirce (2005, p. 164), é "a familiaridade que uma pessoa tem com um signo e que a torna apta a utilizá-lo ou interpretá-lo”.

Desde o início do trabalho os alunos fizeram uso de signos para representar o problema, isto é, signos conectados ao objeto que representaram. Ao serem questionados sobre os diferentes modelos matemáticos que utilizaram para resolver o problema, os alunos afirmaram que o intuito do trio era analisar qual dos modelos poderia ser mais adequado para a situação, conforme relato de E1: 
E1: Quando observamos o decrescimento dos valores apresentados na tabela, não ficava claro se era uma reta ou uma curva exponencial. Daí a gente desenvolveu os dois modelos.

$P$ : E por que vocês escolheram essas duas curvas?

E1: Porque pensamos em conteúdos matemáticos do Ensino Médio e de imediato as curvas que vieram à mente no momento da atividade foram essas. Como seremos professores pensamos em conteúdos desse nível de ensino (E1, entrevista gravada em áudio, 2011).

Ao tratar do que de imediato lhe veio à mente, E1 estava se referindo aos possíveis objetos matemáticos que poderiam utilizar para deduzir o modelo matemático da situação. As curvas são signos que representam de certa forma um objeto matemático. Isso está em consonância com o que é afirmado por Santaella (2007, p. 15), de que um signo que "nos coloca em contato com tudo aquilo que costumamos chamar de realidade”. E essa realidade nessa atividade de modelagem matemática corresponde à situação-problema da qual se originou o problema a ser estudado bem como ao conhecimento que tinham de funções lineares, quadráticas e exponenciais e métodos de construção dessas funções por meio de um conjunto de dados.

Em entrevista, os alunos revelaram que, embora o desenvolvimento desta atividade tenha levado 4 horas/aula, é uma atividade diferente do que geralmente realizam em sala de aula e que, nesse momento, de fazerem sozinhos sentiram o que é experimentar fazer atividade de modelagem, conforme relatou $\mathrm{E} 2$ :

Eu acho que também foi a primeira atividade que nós desenvolvemos sozinhos mesmo. Porque em todas as outras vezes sempre foi durante a aula, então tinha a sua ajuda, tinha a ajuda da professora, [...] mas esse daqui, aí foi autonomia, foi correr atrás mesmo e colocar em prática tudo que tinha visto. Porque às vezes quando você tem ajuda, parece que dá uma relaxada... ah acho que entendi... não pensa tanto. (E2, entrevista gravada em áudio, 2011).

Embora os alunos que fizeram parte do trio considerassem a abordagem do tema $O$ consumo de cigarro uma atividade de modelagem complexa para ser desenvolvida por eles com poucas interferências da professora e da pesquisadora, sentiram-se mais próximos do que é desenvolver uma atividade de modelagem [fala de E1, confirmada por E2] (E1, entrevista gravada em áudio, 2011).

Ao finalizarem a dedução dos modelos matemáticos, levando em consideração um modelo linear e um modelo exponencial, os alunos responderam às questões que lhes foram propostas em questionário posterior.

A questão 1: O que significa, do ponto de vista matemático, o fato de a quantidade de cigarros consumida por habitante no ano de 2010 ser 813 unidades e esperar-se que ocorra uma redução para 702 unidades? foi proposta pela professora e pesquisadora com intuito de que os alunos observassem que a redução do número de cigarros está atrelada em termos matemáticos ao decrescimento de uma função (Figura 11). 


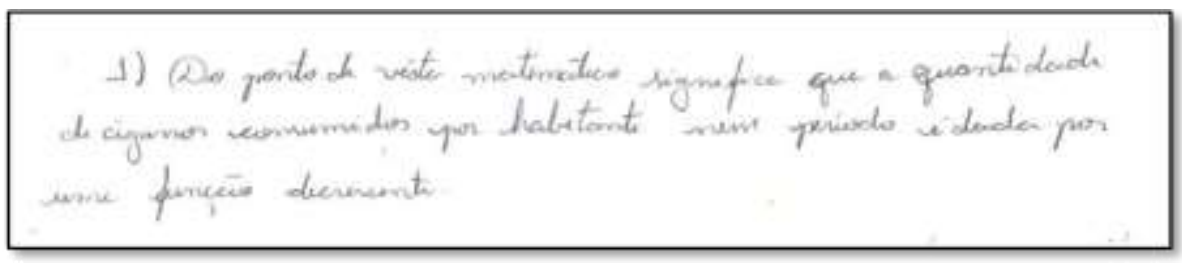

Figura 11- Registro de E1 para a Questão 1 do questionário Fonte: Relatório entregue por E1 (2011).

A resposta para a Questão 1 indica a articulação entre atribuição de significado para objeto matemático e para o problema, pois os alunos entendem que os objetos matemáticos função linear e função exponencial podem representar uma situação que trata de decaimento de um fenômeno - no caso, decrescimento do número de cigarros consumidos.

Uma reflexão que emergiu da situação em estudo é abordada na questão 2: Uma política governamental indicando um rápido decrescimento do número de cigarros consumidos por pessoa por ano deveria usar qual dos modelos matemáticos construídos? Justifique.

Para esta questão, o trio apontou o modelo linear como o que indica um rápido decrescimento do número de cigarros consumidos por pessoa por ano (Figura 12), pois a meta a ser atingida na diminuição do número de cigarros e que era resposta ao problema consistia no ano de 2018 - ano mais próximo do que 2020 quando comparado com o ano em que a atividade de modelagem foi realizada (2011). Nesse comparativo entre os modelos matemáticos obtidos, os alunos reconhecem uma característica dos objetos matemáticos representada pelos signos algébricos com relação ao decrescimento: nesse caso a função linear decresce mais rapidamente do que a função exponencial.

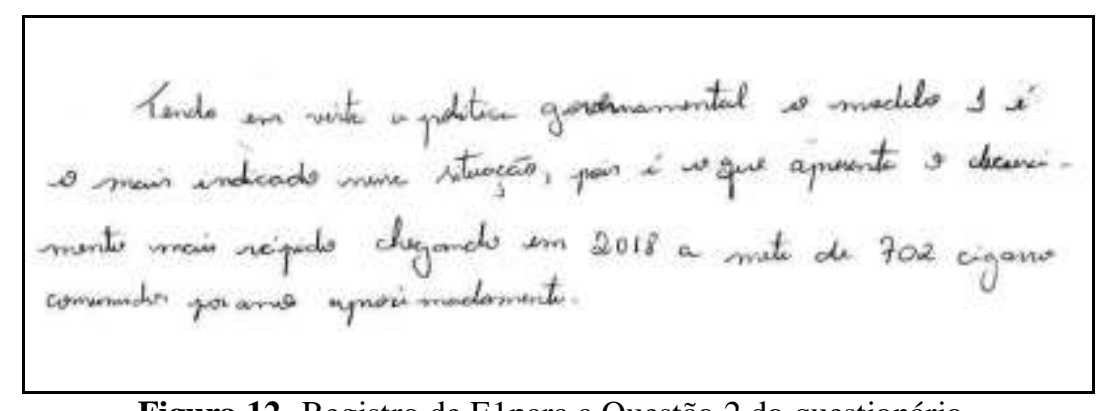

Figura 12- Registro de E1para a Questão 2 do questionário Fonte: Relatório entregue por E1 (2011).

Apesar de a atividade ter sido desenvolvida a partir de dados prontos como caracterizados por Diniz e Borba (2012), o engajamento para abordagens matemáticas e para a resolução do problema possibilitou um estudo da situação mediante modelos construídos pelos alunos, levando-os a definir hipóteses para esta construção bem como a apresentar respostas para o problema em consonância com essas hipóteses, de modo que podemos 
delinear caminhos do significado para o problema e para os objetos matemáticos traçados pelos alunos nessa atividade.

\section{Caminhos do significado na atividade de modelagem matemática}

A descrição das ações dos alunos que apresentamos na seção anterior, nos permite olhar para o movimento do significado, ou pelo menos para uma perspectiva de um movimento e, em sintonia com a assertiva de Colapietro $(2004$, p. 21$)$ de que existe um caminho "somente quando houve um movimento ou pelo menos a perspectiva de movimento".

Fundamentadas na teoria dos interpretantes de Peirce, quando tratamos da atribuição de significado, podemos inferir que os interpretantes produzidos pelos estudantes E1, E2 e E3 que se remetem ao problema e ao objeto matemático em estudo estão relacionados à atribuição de significado para esses objetos. Há evidências de atribuição de significado por meio de familiaridade com o objeto, na intenção de significar o objeto, como uma ideia que se remete ao objeto, como consequência futura para abarcar o objeto, por meio de experiência colateral com o objeto.

Conhecendo as informações que permeavam a situação-problema, inicialmente a atribuição de significado se revela em uma ideia que poderia ser identificada como uma representação mental do problema. Nesta transição da situação-problema para a representação mental, ocorreram mudanças nos símbolos usados por E1, E2 e E3, visto que estavam considerando informações que interferiam na compreensão da situação e que não possibilitavam a estruturação e organização de um problema. Os novos símbolos usados dão indícios de interpretação das informações para delinear o problema e, neste sentido, indicam a atribuição de significado. A conjectura de que políticas governamentais sobre a proibição do fumo em alguns locais contribuem para a diminuição do número de cigarros consumidos por habitante, bem como a análise do comportamento dos dados para os anos de 1990 e 2010 são procedimentos denotativos de significado nesse caso. Estes procedimentos estão alinhados com a assertiva de Peirce (2005, p. 40) de que o "corpo de um símbolo transforma-se lentamente, mas seu significado cresce inevitavelmente, incorpora novos elementos e livra-se de elementos velhos".

Ao abandonarem elementos velhos, ou seja, quando delimitaram um problema a ser estudado como foco da atividade ao invés de abordarem uma discussão sobre as taxas de decrescimento, tiveram que, por consequência, utilizar os dados da Tabela 1 para o 
desenvolvimento da atividade de modelagem, atribuindo significado para o problema. A partir da compreensão do que deveriam fazer na atividade, a atribuição de significado consistiu na intenção de resolver um problema. Na semiótica peirceana, quando há intenção, há atribuição de significado, pois "significado deve envolver uma referência, a intenção" (PEIRCE, 1989, p. 16, grifo do autor). Esta intenção, em certa medida, foi movendo os alunos na resolução do problema usando diferentes procedimentos e diferentes conteúdos matemáticos (função linear e função exponencial).

No que tange a atribuição de significado para o objeto matemático função linear (modelo linear), podemos inferir que ela vem ancorada: na experiência colateral que tinham com o método dos mínimos quadrados para a dedução do modelo matemático; na consequência prática de determinar uma solução para o problema que era o foco e a intenção dos alunos durante o desenvolvimento da atividade. No entanto, a familiaridade com o desenvolvimento de atividades de modelagem conduziu os alunos a operarem matematicamente com o modelo matemático obtido, buscando sua validação para então concluírem que a resposta a que chegaram, em certa medida, era adequada para o que a situação inicial indica: as pessoas voltarão a fumar menos! Neste sentido, os caminhos do significado para o problema e para o modelo linear nesta atividade de modelagem podem ser configurados como representado na Figura 13.

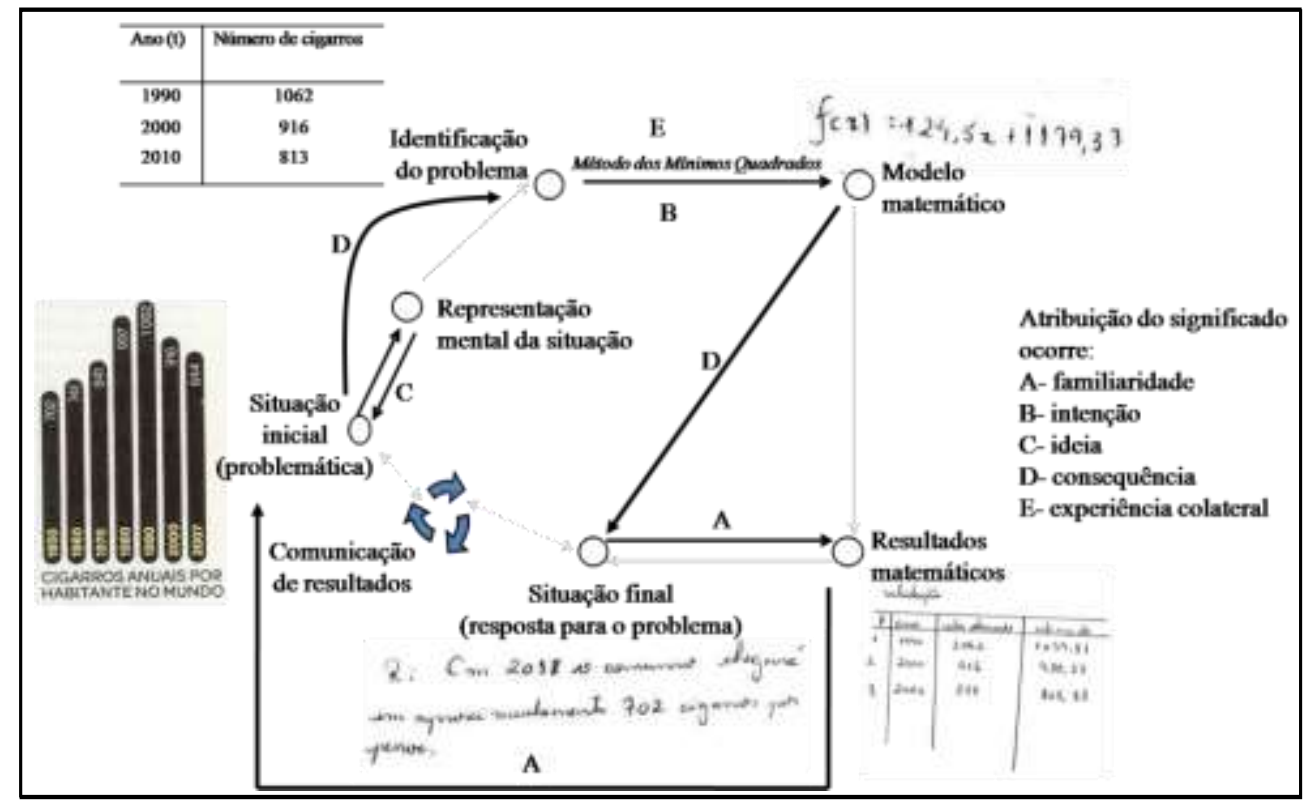

Figura 13 - Caminhos do significado para problema e modelo linear da atividade de modelagem Fonte: Construída pelas autoras para o artigo.

Já para o caso da construção de um modelo exponencial, o que os alunos conhecem sobre decrescimento de um fenômeno e sobre função exponencial, fortalece a atribuição de significado que se evidencia na familiaridade que sinalizam ter com a formulação e resolução 
de equações diferenciais ordinárias e a experiência colateral com o método dos mínimos quadrados para determinar os parâmetros do modelo construído.

Uma vez obtido o modelo, as consequências práticas de operar com este modelo e considerá-lo válido no sentido de que fornece uma solução para o problema configuram um traçado que fortalece nossa inferência sobre a atribuição de significado. Assim, com relação ao problema e ao modelo exponencial, os caminhos do significado nesta atividade de modelagem podem ser configurados como representado na Figura 14.

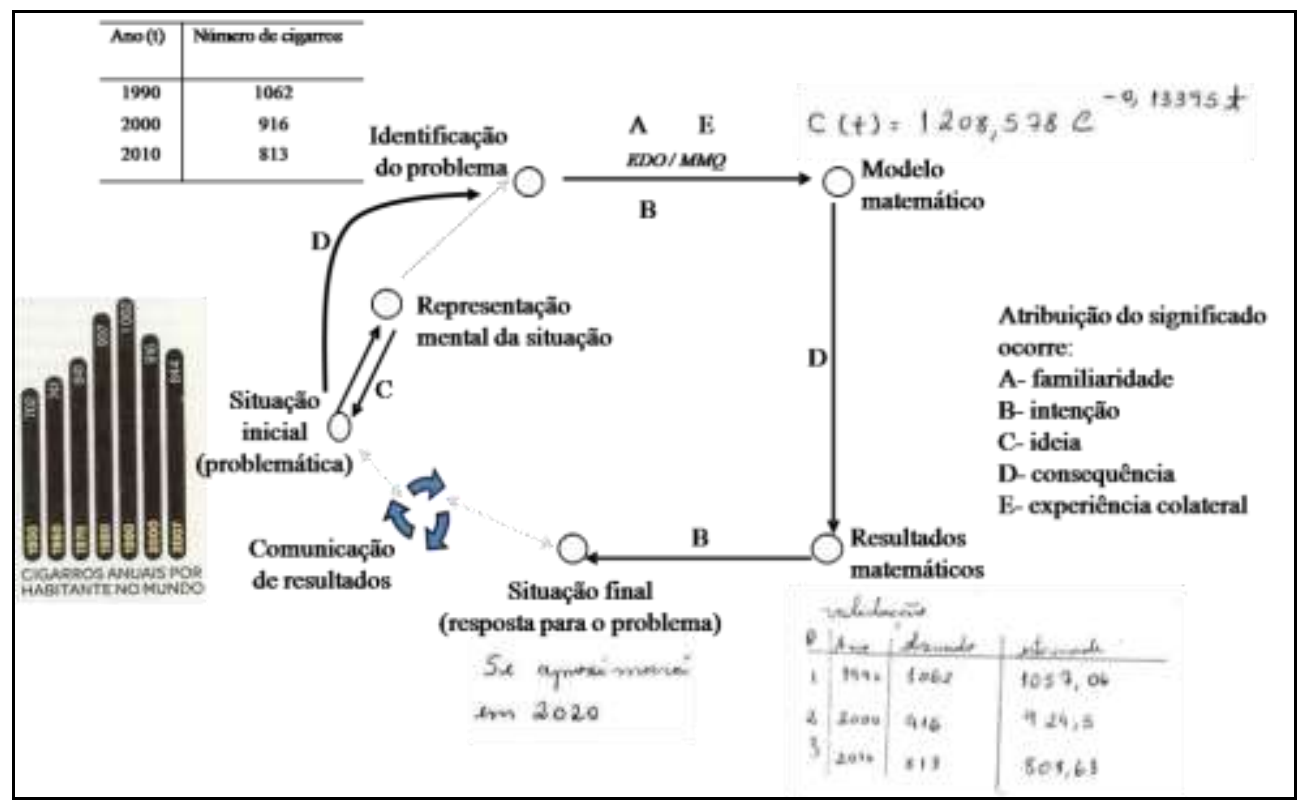

Figura 14- Caminhos do significado para problema e modelo exponencial da atividade de modelagem Fonte: Construída pelas autoras para o artigo.

Levando em consideração os interpretantes produzidos pelos alunos durante o desenvolvimento de uma atividade de modelagem podemos inferir, sob o olhar da semiótica peirceana, que os caminhos do significado em atividades de modelagem matemática se configuram a partir das ações dos alunos em cada uma das etapas da modelagem. Por meio dessas ações, os alunos falam, escrevem, gesticulam, argumentam sobre suas intenções com a atividade, possibilitando-nos inferir sobre os interpretantes que produzem. Esses interpretantes configuram-se em signos que outros alunos podem utilizar para produzirem novos interpretantes em um ciclo ad infinitum para o desenvolvimento da atividade. A intenção dos alunos que desenvolveram a atividade de modelagem apresentada neste artigo era a de dar resposta ao problema que se propuseram a estudar a partir de dados prontos a eles apresentados. A sugestão de problema de um integrante do grupo foi aceita pelos demais que a partir dos interpretantes produzidos fizeram emergir objetos matemáticos que, sob certo aspecto, representam o fenômeno em estudo. 


\section{Referências}

ALMEIDA, L. M. W. Um olhar semiótico sobre modelos e modelagem: metáforas como foco de análise. Zetetiké, Campinas, v. 18, número temático, p. 387-414, dez. 2010.

ALMEIDA, L. M. W.; SILVA, K. A. P. Semiótica e as ações cognitivas dos alunos em atividades de Modelagem Matemática: um olhar sobre os modos de inferência. Ciência \& Educação. Bauru, v. 18, n. 3, p. 623-642, jul./set. 2012.

ALMEIDA, L. W.; SILVA, K. P.; VERTUAN, R. E. Modelagem Matemática na Educação Básica. São Paulo: Contexto, 2012.

BLOMHØJ, M; KJELDSEN, T. H. Students' reflections in Mathematical Modelling Projects. In: KAISER, G. et al. (Ed.). Trends in Teaching and Learning of Mathematical Modelling: international perspectives on the teaching and learning of mathematical modeling. ICTMA 14. New York: Springer, 2011, p. 385-395.

BLUM, W. Can Modelling be taught and learnt? Some answers from empirical research. In: KAISER, G. et al. (Ed.). Trends in Teaching and Learning of Mathematical Modelling: international perspectives on the teaching and learning of mathematical modeling. ICTMA 14. New York: Springer, 2011, p. 15-30.

BLUM, W.; NISS, M. Applied mathematical problem solving, modelling, applications, and links to other subjects - state, trends and issues in mathematics instruction. Educational Studies in Mathematics. Netherlands, v. 22, n.1, p. 37-68, feb. 1991.

BORROMEO FERRI, R. Theoretical and empirical differentiations of phases in the modeling process. ZDM. Berlim, v. 38, n. 2, p. 86-95, april. 2006.

CARREIRA, S.; AMADO, N.; LECOQ, F. Mathematical Modelling of daily life in adult education: focusing on the notion of knowledge. In: KAISER, G. et al. (Ed.). Trends in Teaching and Learning of Mathematical Modelling: international perspectives on the teaching and learning of mathematical modeling. ICTMA 14.New York: Springer, 2011, p. 199-209.

COLAPIETRO, V. The Routes of Significance: Reflections on Peirce's Theory of Interpretants. Cognitio, São Paulo, v. 5, n. 1, p. 11-27, jan./jun. 2004.

DAVIS, P. J; HERSH, R.A experiência matemática. Lisboa: Gradiva, 1995.

DINIZ, L. N.; BORBA, M. C. Leitura e interpretação de dados prontos em um ambiente de modelagem e tecnologias digitais: o mosaico em movimento. Bolema, Rio Claro, v. 26, n. 43, p. 935962, ago. 2012.

HOFFMANN, M. H. G. Learning by developing knowledge networks. ZDM. Berlim, v. 36, n. 6, p.196-205, dec. 2004.

LESH, R. Tools, Researchable Issues \& Conjectures for investigating what it means to Understand Statistics (or Other Topics) Meaningfully. Journal of Mathematical Modelling and Application, Blumenau, v. 1, n. 2, p.16-48, jun. 2010.

MAA $\beta$, K. Barriers and Opportunities for the Integration of Modelling in Mathematic Classes: results of an empirical study. Disponível em: 〈http://www.icme-organisers.dk/tsg20/Maass.pdf> Acesso em: 09 jul. 2006. 
MANECHINE, S. R. S.; CALDEIRA, A. M. A. A significação e ressignificação da linguagem gráfica na compreensão de fenômenos naturais. In: Seminário Internacional de Pesquisa em Educação Matemática, 3., 2006, Água de Lindóia. Anais... Água de Lindóia: SBEM, 2006. p. 1-16.

MISKULIN, R. G. S. et al. A semiótica como campo de análise para as representações de conceitos matemáticos. Cadernos de Semiótica Aplicada. Araraquara, v. 5, n. 2, p. 1-18, dez. 2007.

NÖTH, W. Panorama da semiótica: de Platão a Peirce. 4. ed. São Paulo: Annablume, 2008.

OTTE, M. Mathematical epistemology from a semiotic point of view. In: PME INTERNATIONAL CONFERENCE, 25., 2001, Utrecht. PME... Utrecht: University of Utrecht, The Netherlands, 2001. p. 1-32. Unpublished manuscript.

PEIRCE, C. S. Escritos coligidos. 4. ed. São Paulo: Nova Cultural, 1989. (Os Pensadores).

PEIRCE, C. S. Semiótica. 3. ed. São Paulo: Perspectiva, 2005. (Estudos).

PEIRCE, C. S. Semiótica e Filosofia: textos escolhidos. São Paulo: Cultrix, 1972.

POGGIOLI, L. Estrategias de resolución de problemas. Serie Enseñando a Aprender. Caracas: Polar, 2001. Disponível em: http://www.paideavirtus.cl/mce/PDFS/Ensenando.pdf. Acesso em: 22 abr. 2012.

SANTAELLA, L. A teoria geral dos signos: como as linguagens significam as coisas. 1. ed. São Paulo: Cengage Learning, 2008.

SANTAELLA, L. Matrizes da linguagem e pensamento: sonora visual verbal: aplicações na hipermídia. 3. ed. São Paulo: Iluminuras: FAPESP, 2005.

SANTAELLA, L. Semiótica aplicada. São Paulo: Thomson Learning, 2007.

SILVA, K. A. P. Uma interpretação semiótica de atividades de Modelagem Matemática: implicações para a atribuição de significado. 2013. 285 f. Tese (Doutorado em Ensino de Ciências e Educação Matemática) - Universidade Estadual de Londrina, Londrina, 2013.

STILLMAN, G. et al. A framework for success in implementing Mathematical Modelling in the Secondary Classroom. In: WATSON, J.; BESWICK, K. Annual Conference of the Mathematics Education Research Group of Australia. 30 ${ }^{\text {th }}$, 2007, Wrest Point Hotel Casino, Hobart. Proceedings... Hobart: TAS, 2007. p. 688-697. 